The Economics Profession, the Financial Crisis, and Method

By

David Colander

October 2010

MIDDLEBURY COLLEGE ECONOMICS DISCUSSION PAPER NO. 10-38

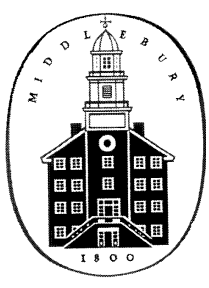

DEPARTMENT OF ECONOMICS

MIDDLEBURY COLLEGE

MIDDLEBURY, VERMONT 05753

http://www.middlebury.edu/ econ 


\section{The Economics Profession, the Financial Crisis, and Method}

In 2007-2008, the world economy came perilously close to a systemic failure in which a financial system collapse almost undermined the entire world economy as we know it. These events have led some to fault the economics profession for its failure to predict the crisis, and to ask whether the crisis will lead the economics profession to change its ways. In this paper, I will discuss these two issues, and then turn to some suggestions for institutional changes in the economics profession that might lead to better outcomes in the future.

\section{Should the economics profession be faulted for its failure to predict the crisis?}

About the time of the financial crisis, a group of economists and mathematical modelers were meeting in Dahlem Germany to discuss the topic, "Is there mathematics of social science?” This group wrote a report entitled The Systemic Failure of the Economics Profession (Colander et al, 2008), which, because of the crisis, was widely circulated and cited by critics of the economics profession as a demonstration that relatively well-known mainstream economists were criticizing the profession. While we were critical of the profession in the report, the specifics of our criticisms have often been misinterpreted. For instance, there has been a tendency to interpret this Dahlem Report as faulting the economics profession for its failure to predict the crisis. That is an incorrect interpretation of our report. We did not believe that the economics profession should be blamed for failing to predict the crisis, because we did not believe the economic crisis was predictable. The underlying themes of our report were that the macro economy is best seen as an evolving complex system that is in many ways unpredictable, and that mathematical modelers should deal with that complexity head on, rather than focus on models that assume much of that complexity away as we believed the dominant dynamic stochastic general equilibrium (DSGE) macroeconomics model did.

While we did not think the crisis could have been predicted, we did severely fault the economics profession for failing to develop and analyze models that, at least, had the possibility of such a failure occurring. We argued that the profession spent far too much time dotting i's and crossing t's on the DSGE model, which, we believed could best be seen as a very small stepping stone towards a complex system model that takes into account forward looking agents. We argued that the DSGE model ruled out meaningful considerations of the financial crises by its representative agent and global rationality assumptions, and that the majority of mainstream macroeconomists continued to explore this limited DSGE model in minute detail, even though the possibility that a crisis might occur at some point was becoming evident to many observers. Our view was that it did not take a rocket economist to recognize problems in the financial sector as the burgeoning sub-prime mortgage market was bringing in less and less credit worthy buyers. At some point, that process of credit expansion had to end.

Our argument was not that economists did not recognize the problems. Our argument was that the large majority had little incentive to study the problems because their perceived incentives were not to study a wide variety of models. This meant that 
very little work was done on highly complex heterogeneous agent, coordination failure models that might have been able to incorporate such events as a crisis of confidence. Instead most macroeconomic researchers kept focused on the DSGE model. Thus, we saw the systemic failure in the economics profession as an incentive compatibility problem. Too many macroeconomists felt that if they did not toe the DSGE line, they were unlikely to be published in journals that would lead to their advancement. The result was that they did not have an incentive to explore alternative models to anywhere near the degree that would have made sense to a neutral observer with educated common sense.

Just as participants in the institutional trenches of financial institutions could see the developing problems but had little incentive to do anything about them, so too could economists see the potential problems, but had little incentive to build models to deal with them. Whereas in the financial sector, the belief was that those who pointed out problems of over-leverage within firms would hurt their chances for advancement, in the academic sector, the belief was that academic economists who introduced models that were complex enough to incorporate the possibility of crises would find that these models were difficult to publish in top journals because those journals were committed to a certain type of so-called micro-grounded DSGE models as the only legitimate approach. This is what we meant by a systemic failure in the economics profession.

Notice that our concern about the economics profession had little to do with mathematics, and, contrary to some critics, we certainly did not see the problem in the economics profession as an overreliance on mathematics. If anything, the problem was that the mathematics being used in macroeconomic models was nowhere near complex enough. To have a reasonable hope of capturing the crisis in a model it was our belief that one most likely needed a complex dynamic nonlinear nested model with many heterogeneous agents, or even agent based nested models. These models are so complex that they do not have analytic solutions nor do they have definite results. They can generally only be solved by simulations. Such models are far more complicated than any used by mainstream DSGE modelers. ${ }^{1}$

We did not claim that these alternative complex systems models would have provided answers, or that those models could have predicted the crisis. Such complex models would most likely have told us that the economy can be unpredictable, and perhaps shed some light on the nature of that unpredictability. Given the complexity of the problem, we believed that a healthy profession would be working on a variety of models, and that it would be engaged in a vigorous debate about what the various models were telling us and which models were better. That was not the case; there was only one dominant model - the DSGE model, which was justified primarily on aesthetic grounds that it was appropriately microfounded. ${ }^{2}$ This we found highly problematic. First, we argued that when studying a complex system, micro and macro issues interrelate, and there are many alternative micro foundations, which could not be considered separately

\footnotetext{
${ }^{1}$ A discussion of these alternative approaches, which I called Post Walrasian, can be found in Colander (2006).

${ }^{2}$ Because of the complexity of the economy and the limited data, empirical methods provided little help in choosing among models.
} 
from the macro context, not a single micro foundation as the DSGE approach assumed. Second, we argued that models of complex systems do not, and at our current stage of knowledge, cannot provide definite policy answers - they simply provide guidance to individuals who have real world experience and a detailed knowledge of the institutional structure. As Keynes said,

Economics is a science of thinking in terms of models joined to the art of choosing models that are relevant to the contemporary world. It is compelled to be this, because, unlike the typical natural science, the material to which it is applied is, in too many respects, not homogeneous through time. ...Good economists are scarce because the gift for using "vigilant observation" to choose good models, although it does not require a highly specialized intellectual technique, appears to be a very rare one. (Keynes 1938)

Given the complexity of the economy and the simplicity of our modeling techniques, our view was that we could not expect much immediate gain for specific policy advice in understanding the macro economy through abstract formal modeling procedures, no matter how complicated. This does not mean that such abstract modeling should not be done; we strongly supported such basic research; it simply means that the modeling should be conducted with appropriate humility about what the model is telling us, and should include warning labels to prevent the model from being misused.

Abstract models add insight into how an economy works; for example, DSGE models included forward looking individuals whose rational actions could undermine the structure of the prevalent macro model. The problem in our view was not the DSGE model per se. By including forward looking individuals the DSGE model was an advance on previous macroeconomic models, and as such could have been an important stepping stone towards developing more complex and meaningful macro models. The problem was that the DSGE model was not used as a stepping stone to much richer models; the problem was that it was the only model being used, and too many researchers felt that they had to use it. This prevented them from creating stepping stones further out in the water. This meant that the economics profession did not explore a multitude of models that could have provided different takes on the macro economy. ${ }^{3}$

This lack of diversity in the models being used was exacerbated by the tendency of some researchers to draw definitive policy conclusions about the economy on the basis of the DSGE-based models they were currently working on, without carefully spelling out the limitations of these models. (See Colander, forthcoming, for a discussion.) We argued that knowingly drawing definitive conclusions about real-world policy from a model that is presented to policy makers as scientific, without appropriately advising policy makers of known limitations of the model, involved an ethical failing on the part of those economists.

\footnotetext{
${ }^{3}$ We should point out that some DSGE researchers were careful to specify the limited usefulness of the DSGE model. See Laidler, 2010.
} 
The same argument about drawing inappropriate policy conclusions from models holds for the efficient market models, which were the foundation of many of the financial instruments that furthered leverage in the credit boom. Again, in our view, there was nothing wrong with these models. They were important for advancing our understanding of how to model forward looking agents. The problem was in how they were used to interpret and influence real world events. In our view, when those models started to be used by real-world institutions, the researchers who understood the problems with that inappropriate use of the models had an ethical duty to point out the model's limitations. This was not generally done. Paul Volcker (WSJ, Dec $\left.14^{\text {th }}, 2009\right)$ tells of sitting next to a world leader in financial engineering listening to a lecture on how financial firms needed to introduce more complex financial instruments based on those mathematical models. Volcker asked him what "all the financial engineering does for the economy." The response was "it does nothing...it moves around the rents in the financial system-and besides, it's a lot of intellectual fun.”

We believe that intellectual fun is important in the scientific process, but we also believe that if one is a scientist, that fun comes with responsibilities. The problem is that non-mathematicians and people not trained in science often have an elevated view of what insights a formal mathematical model is providing, which means that it can be used by individuals inappropriately. Good mathematical modelers recognize the limitations, and we felt that they should see themselves as having an ethical responsibility to make the limitations of their models clear to others when they see their models being misused by others in ways that could cause harm to those other people or to society. Our suggestion was that economists applying models to reality, or developing models that others are applying to reality, needed to be clearer than they have been about the models' limitations. They should include warning labels with the models in order to capture the models' limitations.

\section{Will the crisis lead the economics profession to change its ways?}

Some may think that the colossal failure of the economics profession to develop models relevant to dealing with the crisis would lead the profession to change. In my view, significant change is highly unlikely. The economics profession is primarily an academic profession, which sees itself as primarily concerned with the science of economics, not with hands-on applied policy advice. The institutional structure of the academic economics profession is not structured to reward economists for the correctness of their real world predictions, nor for their understanding of the real economy. Within academia, hands-on research, in which the researcher gains first-hand knowledge through working in the institutions he or she is studying, generally receives little reward. Instead, the academic incentives are designed to reward economists for what I call hands-off applied research, which is research written primarily for other economic researchers. Such hands-off applied research can be useful for policy but it is useful in an indirect way; it is used as background material for policy decisions and often needs to be interpreted by specialists as to what it actually implies for policy.

I am neither arguing that the scientific nature of academic economics research is inappropriate nor that it is irrelevant to policy. I am simply arguing that the abstract 
scientific models that economists work with are not going to respond quickly enough to developments in the real world such as the crisis. Scientific models are, by nature, far removed from actual real world events, which means that there are inevitably hundreds of explanations for why something happened that the models did not predict. A failure of an abstract scientific model to explain a real world event can always be interpreted to mean that more work needs to be done. That is what I expect will happen to the standard DSGE model, and to macroeconomics generally.

I expect reactions such as Eric Maskin's reaction to criticism of the profession for its failures in the financial crisis to be typical. He states, "I don't accept the criticism that economic theory failed to provide a framework for understanding this crisis.....The sort of economics that deserves attack is Alan Greenspan's idealized world, in which financial markets work perfectly well on their own and don't require government actions. There are, of course, still economists - probably fewer than before-who believe in that world. But it is an extreme position and not one likely to be held by those who understand the papers we are talking about” (as cited in Timothy Taylor, 2010). Maskin’s view represents what I believe is a mainstream response to most criticisms of the economics profession for its failures predicting crises such as the recent financial crisis.

Even though the financial crisis will not lead to wholesale changes in how macroeconomics is done, it will have some temporary effects. It has certainly given heterodox critics of the mainstream macro model their fifteen minutes of fame. However, this interest in the more heterodox positions is, I suspect, temporary. By that I mean that the crisis is unlikely to lead to, say, a heterodox Post Keynesian explanation of the crisis becoming the mainstream, or any other fundamental change in how mainstream macro theory is conducted.

The reason why little change will occur is that method is embodied in institutions within which economists work. Unless those institutions change, method will not change. Given current institutions, the mainstream approaches will continue to dominate in much the same way over the past decades. Within mainstream economics, there will be some shuffling; some work on the edge of the mainstream will be given more prominence and some at the center will be given a bit less. But, it will just be a reshuffling of mainstream work, not a replacement of mainstream work with heterodox work.

Viewing method as embodied in institutions is important to understanding how the economics profession evolves. The policy "views" attributed to the profession are the composite views of a large number of economists, most of whom are working on small bits of the economic puzzle. Conventional policy views are not the carefully thought out views of any single individual whose specialty is in integrating the large picture of research into policy. Instead, these conventional views are constructed composite views, arrived at by journalists and other economist watchers who translate the profession's work for lay people. This means that what is seen as the conventional wisdom of economists reflects a biased aggregation procedure that too heavily weights views of economists willing to speak with journalists. 
This method of determining conventional mainstream policy views likely gives those mainstream macro economists who are willing to draw strong policy conclusions from the models much greater weight than they would otherwise receive. The reason is that those mainstream economists who are doing mainstream work, but do not see it as having direct policy relevance, because they believe that policy does not follow directly from models in their current state of development, can only say that their research is not directly relevant for policy. Thus their policy views do not enter into the weighting. Moreover, since self-described heterodox economists do not see themselves as part of the mainstream economics profession, almost by definition they receive almost no weight in this aggregation procedure of the profession's views.

Because the views attributed to the economics profession are an ad hoc weighted average of a small subset of economists, most mainstream economists will likely differ some substantially, from that view. This leads to views such as Maskin's-when the conventional mainstream view seems to fail, they do not see it as mainstream economic view being wrong; instead they believe that it was inappropriate conventional wisdom; what was presented as economist's beliefs, were not in fact economist's beliefs. It also means that changes in the mainstream conventional wisdom can occur as the journalist aggregators change their aggregation methods, even when no economist has changed his or her view. For example, the conventional wisdom is that over the last decades economist's views of policy have swung from Keynesian activist to neo-liberal, and are now swinging back to Keynesian activist. My view is that conventional policy views have only changed slightly during much of this period and that those swings have not been the result of changing economic models. The supposed swings in economists' conventional wisdom have in large part reflected self-reinforcing changing aggregators.

Because most mainstream economists do not believe that the conventional wisdom attributed to economists, reflects his or her views, and there is actually a wide range of policy views held by mainstream economists, the mainstream is not especially fazed by events that do not fit what was seen as the conventional mainstream wisdom, because that aggregated conventional wisdom did not reflect the conventional wisdom held by many members of the mainstream. Many methodological discussions miss this element of the economics profession because they discuss method as if it is a choice variable of what might be called a "representative researcher" searching for the truth. There is no "representative researcher" in the economics profession searching for the truth by reflecting on the nuances of policy in relation to all the limitations of models. That's not what economists are trained to do nor what they have an incentive to do. Instead, there are many different researchers working to advance their careers following their incentives created by the institutional structure within which they work. While a belief of others that a researcher is searching for the truth may play a positive role in advancing an economist's career the incentive to search for the truth is dominated by other more local incentives for a successful researcher.

If it were easy to discover the degree to which a researcher is searching for the truth, it would likely play a more important role. Unfortunately, it is not easy. How one's work relates to searching for the truth is difficult to discern when one is only working on a small part of a broader research program. The large majority of economists aren’t 
trained to, nor do they have an incentive to, look at the broader question of whether the sub research program of which they are a part is on the right or wrong track, or the research program most likely to lead to discovering the truth. Even if they do come to the conclusion that the broader research program is on the wrong track, most researchers have little incentive to abandon it, since doing so will likely destroy much of the specific human capital they have built up. ${ }^{4}$

When method is viewed as embodied in institutions, one gets a different view of how ideas compete within the profession. In the embodied method view, the work that wins out in the mainstream has more to do with local institutional incentives in the profession than with whether that work is a closer approximation to the truth than some other work (Colander, 2009). Thus, in my view, most economists who worked on DSGE models were well aware of the model's serious limitations in describing the real world macro economy. The models became dominant not because they shed the most light on macroeconomic policy issues, but because they were tractable, and working on them was most likely to lead to publications that would advance an economist's career.

As should be clear, my view is that the economics profession is unlikely to respond to the crisis with any sense that it should change. If left to its own devices, the mainstream profession will continue with what it is currently doing, and will only slightly change, with some mainstream researchers moving from the periphery of the mainstream to the center, and others moving the other way. But, at least in the near future, the DSGE model will continue to be the dominant model taught at the graduate level. It should also be clear that I believe that change is necessary.

\section{Three Suggestions for Change}

If change is to occur, it will only occur from exogenous change, which changes the incentive structure facing economists. Such change will only occur through a change in the institutional structure of the profession. In the remainder of this paper, I briefly summarize three changes in the institutional structure of the profession, which could be instituted from outside the profession, and that I believe might lead to positive change. These are not suggestions for economists to change their methods; these are suggestions for changes by funding agencies that will, over time, change economist's methods.

\section{Granting Agencies Should Require Warning Labels on Models}

In the Dahlem Report we argued that the models were not the problem; the problem was that models were used inappropriately. The question is how to get models to be used more appropriately. A simple change could be instituted that would have research funding agencies, such as the National Science Foundation, require publications of models that seem to have policy relevance to include an explicit warning directed at the

\footnotetext{
${ }^{4}$ Leonard Rapping, whose work with Robert Lucas, was seminal in starting the New Classical revolution, is an example of an economist who reflected broadly on his work, and decided that it was not leading to the truth. He never regained his mainstream stature. Another macro researcher wrote Alan Kirman that, after reading Kirman's work, he was convinced that the DSGE approach was not the best way to approach macro. However, he was going to continue working in it because it was too difficult to retool.
} 
non-scientific users of the model. This warning could include a list of what the researchers see as limiting assumptions of the model, and the researcher's belief about whether the model can be used to guide policy. At a minimum, such a requirement to place such warnings on their work would require economists to think directly about such issues, and make it less likely that the models were used for purposes for which they were not designed. ${ }^{5}$

\section{Include a Wider Range of Peers in the Funding Peer Review Process}

A second problem indentified in the Dahlem Report, which the financial crisis highlighted, was the profession's tendency to dot i's and cross t's of a single model rather than to explore multiple models in a creative exploratory way. My suspicion is that this tendency reflects the highly oligopolistic structure of the profession where a small group of intereducated economists becomes the peer review filter through which all "quality" research is filtered. ${ }^{6}$ Put simply, the over focusing on a single model reflects too narrow of an idea genetic pool and too much inbreeding.

The tendency of such inbred peer review has increased as more and more schools have adopted a common generally accepted measure of academic research output. These measures are based on journal article publications and citations weighted by past journal article publications and citations. While such a measure has useful characteristics, the general acceptance of a narrow dimensional "quality weighted” journal article output metric has created a narrow dimension along which researchers at all levels compete for advancement. When the editors of all those highly rated journals have a common educational experience, the result can be a self-fulfilling peer review process that leads most researchers to work on the same type model. Multiple approaches are discouraged, and dotting of i's and crossing of t's of whatever model is currently in vogue is encouraged. ${ }^{7}$

Such a tendency can be countered by an expansion of the peer reviewer pool used by grant-giving foundations such as NSF. This could include specifically including heterodox and other dissenting economists as part of the peer reviewer pool. One of the goals in setting up the pool should be to have a large amount of diversity in that pool. Even more diversity could be included in the reviewer pool by going outside the economics profession. For example, physicists, mathematicians, statisticians, and even business and governmental representatives, could serve, along with economists, on reviewing committees for economics proposals. Such a broader peer review process would likely yield much more reflection by the reviewing committees, and encourage more creative research on a much wider range of models.

\footnotetext{
${ }^{5}$ This proposal is not totally fanciful. In the UK, UK Research Councils Academic Fellows have been appointed. Their responsibility is to communicate the limitations of their models and the potential misuses of their research.

${ }^{6}$ The tendency to focus on a single approach does not necessarily imply that it will be heuristic analysis that is eliminated. It can as well be mathematical economic that is eliminated. In the 1940s, the editors of the American Economic Review rejected a paper by a young economist named Paul Samuelson, as being too theoretical to warrant publication. (Deardorff and Stern, 1994)

${ }^{7}$ The problem is not limited to economics. The problem exists whenever definitive empirical testing of models is impossible. See, for instance, Lee Smolin (2006).
} 


\section{Increase the Number of Researchers Trained to Interpret Models}

A third problem identified in the Dahlem Report was that few economists felt responsible for putting the research being done in policy perspective. Currently, most economists are not selected for their ability to, or trained in how to "choose" an appropriate model, or otherwise relate a model to policy. Doing this requires knowledge of a wide range of models, historical knowledge, and institutional knowledge. They are trained almost entirely to produce models. The other ability they must learn on their own. By design graduate training has eliminated those courses, such as the history of economic thought, methodology, economic history, or courses surveying literature, that are most relevant for training students to choose among, and interpret models.

A potential solution to this problem is change to increase the number of researchers trained in interpreting models rather than developing models. This would mean viewing the interpretation of models as a separate skill from producing models. If a funding agency were to provide research grants specifically to interpret models, that problem could be somewhat alleviated. In a sense, what I am suggesting is the creation of an applied science subdivision of the National Science Foundation's social science division. This subdivision would fund research on the usefulness and interpretation of models.

This interpretative research would require researchers who are comfortable with consuming, but not necessarily producing, highly technical work. But it would also require researchers to have training in methodology, economic history, history of economic thought, the cutting edge work of related fields, a knowledge of institutions, and a sensibility about how the real-world economy works. That sensibility could most likely be gained from having worked in the institutions being modeled, and thus training for this task would likely involve actually working in the institutions that are being studied. This research would involve a quite different set of skills than is currently taught in most graduate economic programs. These are all skills that are currently not taught in graduate economics programs, but they are the skills that underlie judgment and common sense necessary to interpret models. By providing grants for this work, foundations would encourage the development of a group of economists who specialized in interpreting models and applying models to the real world. The development of such a group would go a long way towards placing the necessary warning labels on models, and make it less likely that fiascos like a financial crisis would happen again.

\section{Conclusion}

None of the above suggestions is a panacea. Even if implemented, they will make only a minor change in the incentive structure of the profession, and thus will have only a small influence on method. But, because method is not a direct choice variable of economists, and is instead embodied in the institutional incentives of the profession, implementing the above suggestions are more likely to change the economics profession than any calls for mainstream macro economists to change themselves because of their failure to adequately warn about the potential for a financial crisis. 


\section{Bibliography}

Colander, David. (ed) 2006. Post Walrasian Macroeconomics: Beyond the Dynamic Stochastic General Equilibrium Model Cambridge University Press. Cambridge.

Colander, David. 2009. Economists, "Incentives, Judgment, and the European CVAR Approach to Macroeconometrics” Economics: The Open-Access, Open-Assessment E-Journal, Vol. 3, 2009-9.

Colander, David. forthcoming. “The Keynesian Method, Complexity, and the Training of Economists” in Perspectives on Keynesian Economics, edited by Arie Arnon, Springer.

Colander, David. et al. 2009. "The Financial Crisis and the Systemic Failure of the Economics Profession” Critical Review. Vol. 21:2-3, 249-267.

Deardorff, Alan and Robert Stern. 1994. The Stolper-Samuelson Theorem: A Golden Jubilee, Ann Arbor: University of Michigan Press.

Keynes, J.M. 1938. Letter to Roy Harrod. 4, July. http://economia.unipv.it/harrod/edition/editionstuff/rfh.346.htm

Laidler, David. 2010. “Lucas, Keynes, and the Crisis” Journal of the History of Economic Thought. March. Vol. 32:1, 39-62.

Smolin, Lee, 2006. The Trouble with Physics, Houghton Mifflin, Boston.

Taylor, Timothy. 2010. “Recommendations for Further Reading” Journal of Economic Perspectives. Spring. Vol. 24:2, 227-234.

Volcker, Paul. 2009. “Paul Volcker: Think More Boldly” Wall Street Journal, Dec $14^{\text {th }}$. http://online.wsj.com/article/SB10001424052748704825504574586330960597134.ht $\underline{\mathrm{ml}}$ 